\title{
openheart Effect of moderate potassium-elevating treatment in long QT syndrome: the TriQarr Potassium Study
}

Peter Marstrand (D , , Kasim Almatlouh, ${ }^{1}$ Jørgen K Kanters, ${ }^{2}$ Claus Graff, ${ }^{3}$ Alex Hørby Christensen, ${ }^{1}$ Henning Bundgaard, ${ }^{4}$ Juliane Theilade ${ }^{1}$

\begin{abstract}
- Additional supplemental material is published online only. To view, please visit the journal online (http://dx.doi.org/10.
\end{abstract} 1136/openhrt-2021-001670).

To cite: Marstrand $\mathrm{P}$, Almatlouh $\mathrm{K}$, Kanters JK, et al. Effect of moderate potassiumelevating treatment in long $Q T$ syndrome: the TriQarr Potassium Study. Open Heart 2021;8:e001670. doi:10.1136/ openhrt-2021-001670

Received 3 April 2021 Accepted 27 August 2021

Check for updates

(c) Author(s) (or their employer(s)) 2021. Re-use permitted under CC BY-NC. No commercial re-use. See rights and permissions. Published by BMJ.

${ }^{1}$ Department of Cardiology, Herlev-Gentofte Hospital, Copenhagen University Hospital, Copenhagen, Denmark ${ }^{2}$ Laboratory of Experimental Cardiology, Department of Biomedical Sciences, University of Copenhagen, Copenhagen, Denmark

${ }^{3}$ Department of Health Science and Technology, Aalborg University, Aalborg, Denmark ${ }^{4}$ Department of Cardiology, Rigshospitalet, Copenhagen University Hospital, Copenhagen, Denmark

Correspondence to Dr Peter Marstrand; pmarstrand@hotmail.com

\section{ABSTRACT}

Background In long QT syndrome (LQTS), beta blockers prevent arrhythmias. As a supplement, means to increase potassium has been suggested. We set to investigate the effect of moderate potassium elevation on cardiac repolarisation.

Methods Patients with LQTS with a disease-causing $K C N Q 1$ or $K C N H 2$ variant were included. In addition to usual beta-blocker treatment, patients were prescribed (1) $50 \mathrm{mg}$ spironolactone (low dose) or (2) $100 \mathrm{mg}$ spironolactone and $3 \mathrm{~g}$ potassium chloride per day (high dose+). Electrocardiographic measures were obtained at baseline and after 7 days of treatment.

Results Twenty patients were enrolled (10 low dose and 10 high dose+). One patient was excluded due to severe influenza-like symptoms, and 5 of 19 patients completing the study had mild side effects. Plasma potassium in low dose did not increase in response to treatment $(4.26 \pm 0.22$ to $4.05 \pm 0.19 \mathrm{mmol} / \mathrm{L}, \mathrm{p}=0.07$ ). Also, no change was observed in resting QTcF (QT interval corrected using Fridericia's formula) before versus after treatment (478 \pm 7 vs $479 \pm 7 \mathrm{~ms}, \mathrm{p}=0.9$ ). In high dose+, potassium increased significantly from $4.08 \pm 0.29$ to $4.48 \pm 0.54 \mathrm{mmol} / \mathrm{L}$ $(p=0.001)$. However, no difference in QTcF was observed comparing before $(472 \pm 8 \mathrm{~ms})$ versus after $(469 \pm 8 \mathrm{~ms})$ $(p=0.66)$ high dose + treatment. No patients developed hyperkalaemia.

Conclusion In patients with LQTS, high dose + treatment increased plasma potassium by $0.4 \mathrm{mmol} / \mathrm{L}$ without cases of hyperkalaemia. However, the potassium increase did not shorten the QT interval and several patients had side effects. Considering the QT interval as a proxy for arrhythmic risk, our data do not support that potassiumelevating treatment has a role as antiarrhythmic prophylaxis in patients with LQTS with normal-range potassium levels.

Trial registration number NCT03291145.

\section{INTRODUCTION}

In patients with congenital long QT syndrome (LQTS), beta blockers effectively prevent syncope and sudden cardiac death. ${ }^{1}$ Unfortunately, side effects may prohibit treatment or patients may experience arrhythmic events despite beta-blocker therapy. ${ }^{1}$ In patients with recurrent syncope or breakthrough

\section{Key questions}

What is already known about this subject?

- Potassium-elevating treatment has been suggested as an antiarrhythmic therapy in patients with long QT syndrome (LQTS).

What does this study add?

- Daily intake of $100 \mathrm{mg}$ spironolactone and potassium supplements increased plasma potassium by $0.4 \mathrm{mmol} / \mathrm{L}$. However, this modest increase did not shorten cardiac repolarisation in static or dynamic ECG recordings in LQTS types 1 and 2.

How might this impact on clinical practice?

- Current data do not support that moderate elevation of plasma potassium has a role for long-term antiarrhythmic prophylaxis in patients with LQTS with normal potassium levels.

arrhythmias despite beta-blocker treatment, guidelines suggest considering an implantable cardioverter defibrillator (ICD) and/or left cardiac sympathetic denervation. ${ }^{23}$ As a non-invasive supplement, elevating plasma potassium concentration by spironolactone in combination with potassium supplements has been suggested. ${ }^{45}$ The first experimental study by Compton et a $\tilde{e}$ found that repolarisation, both length of QT interval and T-wave morphology, normalised in KCNH2 (LQTS2) patients when increasing serum potassium by $\geq 1.5 \mathrm{mmol} / \mathrm{L}$. This study was followed by a clinical study by Etheridge $e t$ al treating eight patients with LQTS2 for 4 weeks. They increased serum potassium by $1.2 \mathrm{mmol} / \mathrm{L}$ and found a dramatic shortening of the QTcB from 526 to $423 \mathrm{~ms}$. Still, data remain very limited, and due to the potential risk of hyperkalaemia ${ }^{6}$ the clinical use is limited and not recommended as standard treatment by guidelines. ${ }^{23}$ In this study, we set to investigate the effect of modestly increasing plasma potassium by spironolactone and potassium supplements in clinically relevant doses 
on duration of the repolarisation as a proxy for risk of ventricular arrhythmia.

\section{METHODS}

\section{Clinical inclusion}

Patients with LQTS in active beta-blocker treatment and with a variant in KCNQ1 or KCNH2 (LQTS1 or LQTS2) were prospectively included at the Herlev-Gentofte Hospital, Copenhagen University Hospital, as part of the TriQarr project, which explored the mechanism of QT prolongation. ${ }^{7}$ When arriving at our clinic, patients took their usual beta blocker. One hour after intake, electrocardiograms were recorded after a minimum of $5 \mathrm{~min}$ of rest and during change from supine position to standing-'brisk standing,. 8

In addition to the usual beta-blocker treatment, the first 10 patients were prescribed $50 \mathrm{mg}$ of spironolactone $(50 \mathrm{mg} \times 1$, low dose) per day. After assessing the effect on potassium levels in the low dose group, the latter 10 patients were prescribed $100 \mathrm{mg}$ spironolactone (50 mg $\times 2$ ) and orally $3 \mathrm{~g}$ potassium chloride $(750 \mathrm{mg}$ Kaleorid $\times 4 \sim 40 \mathrm{mmol}$ potassium) per day (high dose+). Tablets were administered to patients in a 7-day tablet box, which secured $100 \%$ compliance from all patients (tablet counting). After 7 days on potassium-elevating treatment, ECGs at rest and during brisk standing were obtained 1 hour after intake of usual beta blocker. All electrolyte concentrations were reported as plasma concentrations as this has become standard in Danish hospitals.

\section{ECG measurements}

Continuous ECG monitoring was conducted by 12-lead Holter monitoring (Life card CF, Spacelabs Healthcare) through all sessions. Holter ECGs were uploaded into the Sentinel Cardiology Information Management System. In this study, we tried to apply the brisk standing test to investigate the role of increasing potassium during heart rate accelerations and potentially measure a difference. QT intervals were measured by PM and JT, blinded using the tangent principle ${ }^{9}$ at baseline, defined as the last electrical cycle before standing up and at $\max H R$, defined as the single beat with the fastest heart rate. The tangent method was used both before and after treatment and chosen for its low interobserver variability, although this method could theoretically underestimate a beneficial effect of treatment.

To assess automatic QT measurement, the recordings were split into $10 \mathrm{~s}$ ECG sampled at $500 \mathrm{~Hz}$ and analysed using V.243 of the 12SL algorithm (GE Healthcare, Milwaukee, Wisconsin, USA), which superimposes all 12 leads to measure the QT interval from earliest onset to latest offset in any lead. All QT intervals were corrected using Fridericia's formula, $\mathrm{QTcF}=\mathrm{QT} /(\mathrm{RR})^{1 / 3}$, and Bazett's formula, $\mathrm{QTcB}=\mathrm{QT} /(\mathrm{RR})^{1 / 2}$.

\section{Morphology of the T wave}

T-wave Morphology Combination Score (MCS) and its subcomponents (flatness, asymmetry and notches) were measured with QT Guard Plus (GE Healthcare). MCS is a unitless marker, combining the asymmetry, flatness and notching of the $\mathrm{T}$ wave into a combined score. ${ }^{10}$ The normal $\mathrm{T}$ wave has an MCS of $0.71 \pm 0.24$, and a higher MCS indicates a deviation from the normal T wave associated with blockage or loss of function of the cardiac repolarisation. The MCS score has previously been described in detail. ${ }^{10}$

\section{Statistics}

Continuous variables were expressed as mean $\pm \mathrm{SD}$ measurements of heart rate, and QT intervals were expressed as mean $\pm \mathrm{SEM}$ and compared before versus after treatment using a paired t-test. Differences in categorical variables were calculated using Fisher's exact test. An intraclass correlation coefficient (ICC) was calculated (twoway, single measures and absolute agreement) to assess interobserver variability. An ICC $>0.70$ was considered excellent. For all analyses, a $p$ value of $<0.05$ was considered statistically significant. R V.3.6.1 was used for all analyses. ${ }^{11}$

\section{RESULTS}

A total of 20 patients were included: 10 in the low dose and 10 in high dose+ (table 1). The mean age of the whole cohort was $39 \pm 10$ and $17(85 \%)$ were women. One patient in the low dose group experienced severe influenza-like symptoms on day 3; spironolactone was discontinued, and the patient was excluded from clinical testing analyses. None of the patients reported any cardiac events or symptoms during the treatment period.

\section{Low dose}

Of the 10 patients, $3(30 \%)$ were LQTS1 and $7(70 \%)$ were LQTS2 patients (list of specific mutations in online supplemental table 1). Eight ( $80 \%$ ) were women and the mean age was $37 \pm 12$ at the time of the study. Five $(50 \%)$ of the patients had a family history of sudden cardiac death before 60 years of age, and one $(10 \%)$ had a history of syncope or ventricular tachycardia. Seven $(70 \%)$ patients were in treatment with metoprolol $86 \pm 24 \mathrm{mg} /$ day, and three were treated with atenolol $33 \pm 14 \mathrm{mg} /$ day.

At baseline visit, systolic blood pressure was $121 \pm 12$ $\mathrm{mm} \mathrm{Hg}$, which was significantly reduced to $112 \pm 12$ after 7 days of study treatment ( $\mathrm{p}=0.018$ ) (table 2 and online supplemental figure 1).

There was no increase observed in plasma potassium after 7 days of $50 \mathrm{mg}$ spironolactone $(4.26 \pm 0.22$ to $4.05 \pm 0.19 \mathrm{mmol} / \mathrm{L}, \mathrm{p}=0.07$ ) but a borderline decrease (figure 1). Unfortunately, the potassium test of one low dose patient haemolysed; thus, only eight tests were used in this preanalysis/postanalysis of potassium.

The low dose spironolactone did also not affect plasma sodium (141.7 \pm 0.26 to $140.1 \pm 2.1 \mathrm{mmol} / \mathrm{L}, \quad \mathrm{p}=0.11)$ (figure 1), magnesium $(0.87 \pm 0.04$ to $0.84 \pm 0.06 \mathrm{mmol} / \mathrm{L}$, $\mathrm{p}=0.2)$ or glucose $(5.1 \pm 0.5$ to $5.5 \pm 0.8 \mathrm{mmol} / \mathrm{L}, \mathrm{p}=0.2)$. The eGFR was significantly reduced from $106 \pm 17$ to $97 \pm 18(\mathrm{p}=0.043)$. 
Table 1 Baseline characteristics

\begin{tabular}{|c|c|c|}
\hline & $\begin{array}{l}\text { Low dose } \\
\text { Spironolactone } 50 \\
\mathrm{mg}\end{array}$ & $\begin{array}{l}\text { High dose+ } \\
\text { Spironolactone } 100 \\
\text { mg+3 g potassium } \\
\text { chloride }\end{array}$ \\
\hline & $\mathrm{N}=10^{*}$ & $N=10$ \\
\hline Female sex, n (\%) & $8(80)$ & $9(90)$ \\
\hline $\begin{array}{l}\text { Age (years), } \\
\text { mean } \pm S D\end{array}$ & $36.9 \pm 11.9$ & $41.5 \pm 6.9$ \\
\hline $\mathrm{BMI}$, mean $\pm \mathrm{SD}$ & $24.7 \pm 2.6$ & $23.2 \pm 5.5$ \\
\hline $\begin{array}{l}\text { Spironolactone dose } \\
(\mathrm{mg} / \mathrm{kg})\end{array}$ & $0.73 \pm 0.14$ & $1.57 \pm 0.27$ \\
\hline \multicolumn{3}{|l|}{ Genetics, n (\%) } \\
\hline LQTS1 & $3(30)$ & $5(50)$ \\
\hline LQTS2 & $7(70)$ & $5(50)$ \\
\hline Proband, n (\%) & $2(20)$ & $6(60)$ \\
\hline ICD, n (\%) & $0(0)$ & $2(20)$ \\
\hline Syncope/VT, n (\%) & $1(10)$ & $4(40)$ \\
\hline $\begin{array}{l}\text { Sudden cardiac } \\
\text { death in family } \\
\text { before } 60 \text { years of } \\
\text { age, } n(\%)\end{array}$ & $5(50)$ & $1(10)$ \\
\hline \multicolumn{3}{|c|}{ Beta-blocker treatment } \\
\hline Metoprolol, n (\%) & $7(70)$ & $6(60)$ \\
\hline $\begin{array}{l}\text { Dose }(\mathrm{mg}) \\
\text { mean } \pm S D\end{array}$ & $86 \pm 24,70$ & $96 \pm 40$ \\
\hline Atenolol, $\mathrm{n}(\%)$ & $3(30), 73$ & $3(30), 67$ \\
\hline $\begin{array}{l}\text { Dose }(\mathrm{mg}) \\
\text { mean } \pm S D\end{array}$ & $33 \pm 14$ & $50 \pm 0$ \\
\hline Nebivolol, n (\%) & $0(0)$ & $1(10)$ \\
\hline $\begin{array}{l}\text { Dose } \\
(\mathrm{mg}), \text { mean } \pm S D\end{array}$ & & $2.5 \pm 0$ \\
\hline
\end{tabular}

*Including the patient who did not complete treatment due to side effects.

BMI, body mass index; ICD, implantable cardioverter defibrillator; VT, ventricular tachycardia.

\section{ECG findings}

At baseline, the heart rate was $50 \pm 2$ beats $/ \mathrm{min}$, which was not significantly different from the heart rate after 1 week of treatment, $55 \pm 2$ beats $/ \mathrm{min}(\mathrm{p}=0.11)$. No difference in QTcF was observed comparing before ( $478 \pm 7 \mathrm{~ms})$ versus after $(479 \pm 7 \mathrm{~ms})(\mathrm{p}=0.9)$ treatment with spironolactone. The QTcF observed at max heart rate during brisk standing (figure 2) also did not change in response to treatment before $(542 \pm 8 \mathrm{~ms})$ versus after $(536 \pm 9 \mathrm{~ms})$ $(\mathrm{p}=0.4$ ) (figure 3). Individual changes in $\mathrm{QTcF}$ and heart rate are depicted in online supplemental figure 2. QTcFs depicted based on genetic variant are found in online supplemental figure 3. QT intervals were corrected using Bazett's formula in online supplemental figure 4 .

Similar results were found using automatic measurement of heart rate: before $53 \pm 2$ vs $57 \pm$ two bpm after $(\mathrm{p}=0.06)$, QTcF: before $492 \pm 8$ vs $494 \pm 10 \mathrm{~ms}$ after $(\mathrm{p}=0.8)$ and MCS score: before $1.55 \pm 0.20$ vs $1.50 \pm 0.17$ after $(\mathrm{p}=0.7)$.

\section{High dose+}

Of the 10 patients treated with high dose+, five $(50 \%)$ patients were LQTS1 and five (50\%) patients were LQTS2. Nine $(90 \%)$ were women and the mean age was $42 \pm 7$ at the time of study. Two (20\%) were ICD carriers and four $(40 \%)$ had history of syncope or ventricular tachycardia. One $(10 \%)$ of the patients had a family history of sudden cardiac death before 60 years of age. Six $(60 \%)$ patients were treated with metoprolol at a dose of $96 \pm 40 \mathrm{mg} /$ day; three $(30 \%)$ were treated with atenolol at a dose of 50 $\mathrm{mg} /$ day; and one $(10 \%)$ patient was treated with nebivolol $2.5 \mathrm{mg}$ /day.

At baseline visit, systolic blood pressure was $117 \pm 9 \mathrm{~mm}$ $\mathrm{Hg}$, which was significantly reduced to $111 \pm 10 \mathrm{~mm} \mathrm{Hg}$ after 7 days of high dose + treatment $(\mathrm{p}=0.022)$ (table 2$)$.

Plasma potassium was significantly increased from $4.08 \pm 0.29$ to $4.48 \pm 0.54 \mathrm{mmol} / \mathrm{L}(\mathrm{p}=0.001)$ (figure 1$)$. Conversely, plasma sodium was significantly lowered from $141.2 \pm 1.5$ to $139.6 \pm 1.5 \mathrm{mmol} / \mathrm{L}(\mathrm{p}=0.005)$. Also, eGFR was significantly reduced from $99 \pm 15$ to $87 \pm 14(p=0.003)$. There were no changes in magnesium from $0.83 \pm 0.06$ to $0.81 \pm 0.06 \mathrm{mmol} / \mathrm{L}(\mathrm{p}=0.3)$, or glucose from $5.1 \pm 0.5$ to $5.1 \pm 0.7 \mathrm{mmol} / \mathrm{L}(\mathrm{p}=0.9)$.

\section{ECG findings}

At baseline, the heart rate was $51 \pm 2$ beats $/ \mathrm{min}$, which was similar after 1 week of treatment, $54 \pm 2$ beats $/ \mathrm{min}(\mathrm{p}=0.4)$. No difference in QTcF was observed comparing before $(472 \pm 8 \mathrm{~ms})$ versus after $(469 \pm 8 \mathrm{~ms}) \quad(\mathrm{p}=0.6)$ treatment with high dose+. The QTcF observed at max heart rate during brisk standing also did not change in response to treatment before $(520 \pm 10 \mathrm{~ms})$ versus after $(523 \pm 13 \mathrm{~ms})$ $(\mathrm{p}=0.7)$.

Similar results were found using automatic measurement of heart rate: before, $54 \pm 1$ beats $/ \mathrm{min}$, vs after, $56 \pm 2$ beats/min $(\mathrm{p}=0.5)$; QTcF: before, $485 \pm 8 \mathrm{~ms}$, vs after, $483 \pm 7 \mathrm{~ms}(\mathrm{p}=0.7)$; and MCS score: before, $1.57 \pm 0.24$, vs after, $1.65 \pm 0.24(\mathrm{p}=0.4)$.

\section{Interobserver variability}

An intraclass correlation of 0.85 (95\% CI 0.76 to 0.90 ) was calculated, showing excellent agreement between readers.

\section{Side effects of treatment}

Of the nine patients in the low dose group completing 1 week of treatment, one patient reported fatigue in response to treatment. Of the 10 patients in the high dose+ group, four patients (40\%) experienced mild side effects: fatigue $(n=1)$, headache $(n=1)$, nausea $(n=1)$ and influenza-like symptoms $(\mathrm{n}=1)$.

\section{DISCUSSION}

Our study systematically investigated the impact of moderate potassium-elevating treatment in patients with 
Table 2 Clinical testing before and after treatment with potassium-elevating treatment in addition to usual treatment

\begin{tabular}{|c|c|c|c|c|c|c|}
\hline \multirow{2}{*}{$\begin{array}{l}\text { Treatment regime } \\
\\
\text { Time and comparison }\end{array}$} & \multicolumn{3}{|c|}{$\begin{array}{l}\text { Low dose } \\
\text { Spironolactone } 50 \mathrm{mg} \\
\mathrm{N}=9\end{array}$} & \multicolumn{3}{|c|}{$\begin{array}{l}\text { High dose }+ \\
\text { Spironolactone } 100 \mathrm{mg}+3 \mathrm{~g} \text { potassium } \\
\text { chloride } \\
\mathrm{N}=10\end{array}$} \\
\hline & $\begin{array}{l}\text { Before } \\
\text { treatment }\end{array}$ & $\begin{array}{l}\text { After } \\
\text { treatment }\end{array}$ & $\begin{array}{l}P \text { value } \\
\text { before versus } \\
\text { after }\end{array}$ & $\begin{array}{l}\text { Before } \\
\text { treatment }\end{array}$ & After treatment & $\begin{array}{l}P \text { value } \\
\text { before } \\
\text { versus } \\
\text { after }\end{array}$ \\
\hline \multicolumn{7}{|l|}{ Blood pressure } \\
\hline Systolic $(\mathrm{mm} \mathrm{Hg})$, mean $\pm \mathrm{SD}$ & $117.9 \pm 12.0$ & $111.9 \pm 12.3$ & 0.018 & $117.0 \pm 9.3$ & $110.7 \pm 9.9$ & 0.022 \\
\hline Diastolic $(\mathrm{mm} \mathrm{Hg})$, mean $\pm \mathrm{SD}$ & $74.7 \pm 10.9$ & $70.6 \pm 9.5$ & 0.10 & $68.3 \pm 6.9$ & $66.4 \pm 7.1$ & 0.30 \\
\hline \multicolumn{7}{|l|}{ Blood tests } \\
\hline Potassium (mmol/L), mean $\pm \mathrm{SD}$ & $4.26 \pm 0.22$ & $4.05 \pm 0.19$ & 0.072 & $4.08 \pm 0.29$ & $4.48 \pm 0.54$ & 0.001 \\
\hline Sodium (mmol/L), mean \pm SD & $141.7 \pm 2.6$ & $140.1 \pm 2.1$ & 0.11 & $141.20 \pm 1.48$ & $139.60 \pm 1.51$ & 0.005 \\
\hline Magnesium (mmol/L), mean \pm SD & $0.87 \pm 0.04$ & $0.84 \pm 0.06$ & 0.18 & $0.83 \pm 0.06$ & $0.81 \pm 0.06$ & 0.29 \\
\hline Glucose (mmol/L), mean $\pm \mathrm{SD}$ & $5.11 \pm 0.50$ & $5.50 \pm 0.75$ & 0.17 & $5.09 \pm 0.54$ & $5.06 \pm 0.74$ & 0.89 \\
\hline eGFR $\left(\mathrm{mL} / \mathrm{min} / 1.73 \mathrm{~m}^{2}\right)$, mean $\pm \mathrm{SD}$ & $105.6 \pm 16.9$ & $97.4 \pm 18.3$ & 0.043 & $99.0 \pm 14.6$ & $86.6 \pm 14.2$ & 0.003 \\
\hline \multicolumn{7}{|l|}{ ECG measures-Manuel } \\
\hline HR, baseline, mean \pm SEM & $50.1 \pm 2.3$ & $55.0 \pm 1.8$ & 0.11 & $51.4 \pm 2.2$ & $53.7 \pm 2.0$ & 0.42 \\
\hline HR at max heart rate, mean \pm SEM & $83.1 \pm 2.7$ & $82.0 \pm 4.0$ & 0.58 & $73.7 \pm 3.0$ & $78.4 \pm 3.6$ & 0.27 \\
\hline$\Delta \mathrm{HR}$, max heart rate, mean $\pm \mathrm{SEM}$ & $33.0 \pm 2.4$ & $27.0 \pm 1.9$ & $<0.001$ & $22.3 \pm 2.4$ & $24.7 \pm 3.0$ & 0.28 \\
\hline $\begin{array}{l}\text { Time from baseline to max heart rate } \\
\text { (s), mean } \pm \text { SEM }\end{array}$ & $9.9 \pm 0.8$ & $8.9 \pm 0.8$ & 0.06 & $9.4 \pm 0.8$ & $10.5 \pm 1.1$ & 0.33 \\
\hline \multicolumn{7}{|l|}{ Fridericia’s correction } \\
\hline QTcF, baseline, mean \pm SEM & $477.9 \pm 7.2$ & $478.5 \pm 7.3$ & 0.94 & $471.9 \pm 8.1$ & $468.9 \pm 8.0$ & 0.66 \\
\hline QTCF, max heart rate, mean \pm SEM & $542.2 \pm 8.0$ & $536.0 \pm 9.4$ & 0.39 & $519.9 \pm 10.1$ & $523.0 \pm 12.5$ & 0.65 \\
\hline$\triangle Q T c F$, max heart rate, mean \pm SEM & $64.4 \pm 3.5$ & $57.4 \pm 3.7$ & 0.11 & $48.0 \pm 5.5$ & $54.1 \pm 8.6$ & 0.41 \\
\hline \multicolumn{7}{|l|}{ Bazett's correction } \\
\hline QTcB, baseline, mean \pm SEM & $463.5 \pm 9.7$ & $471.5 \pm 7.7$ & 0.062 & $459.8 \pm 10.7$ & $460.1 \pm 9.5$ & 0.98 \\
\hline QTCB, max heart rate, mean \pm SEM & $571.9 \pm 11.3$ & $564.4 \pm 11.3$ & 0.20 & $537.8 \pm 12.9$ & $546.5 \pm 15.3$ & 0.47 \\
\hline$\triangle Q T c B$, max heart rate, mean \pm SEM & $108.4 \pm 5.8$ & $93.0 \pm 6.0$ & 0.016 & $78.0 \pm 7.7$ & $86.4 \pm 11.8$ & 0.36 \\
\hline \multicolumn{7}{|l|}{ Automatic-12SL } \\
\hline $\mathrm{HR}$, baseline, mean $\pm \mathrm{SEM}$ & $52.5 \pm 2.3$ & $57.3 \pm 1.8$ & 0.06 & $53.6 \pm 1.2$ & $55.5 \pm 1.7$ & 0.45 \\
\hline QTcF, baseline, mean \pm SEM & $490.2 \pm 8.1$ & $492.9 \pm 9.7$ & 0.73 & $484.9 \pm 7.9$ & $483.2 \pm 7.4$ & 0.66 \\
\hline QTcB, baseline, mean+SEM & $479.2 \pm 10.4$ & $488.9 \pm 9.6$ & 0.20 & $475.6 \pm 6.8$ & $476.7 \pm 7.5$ & 0.80 \\
\hline MCS, baseline, mean \pm SEM & $1.551 \pm 0.196$ & $1.499 \pm 0.167$ & 0.73 & $1.570 \pm 0.237$ & $1.651 \pm 0.236$ & 0.35 \\
\hline
\end{tabular}

eGFR, estimated glomerular filtration rate; max, maximum.

LQTS. In our relatively young primarily female cohort, 50 $\mathrm{mg}$ of spironolactone did neither increase plasma potassium nor shorten cardiac repolarisation. Treating with $100 \mathrm{mg}$ of spironolactone and potassium supplement, we were able to significantly increase plasma potassium by $0.4 \mathrm{mmol} / \mathrm{L}$-but this modest potassium increase had no shortening impact on the repolarisation. Using the QT interval as a proxy for arrhythmic risk, it is therefore questionable if modestly increasing plasma potassium within normal range has any clinical relevance as long-term antiarrhythmic therapy.
In 2001, Etheridge et $a t^{4}$ published groundbreaking results, showing great benefits of potassium-elevating treatment in LQTS2 patients. In the study, eight patients, including four children $(<16$ years), were treated with a mean dose of $250 \mathrm{mg}$ spironolactone (up to 400 $\mathrm{mg}$ )+mean dose of $220 \mathrm{mmol}$ potassium supplements for 4 weeks. This resulted in an increase of serum potassium from $4.0 \mathrm{mmol} / \mathrm{L}$ to $5.2 \mathrm{mmol} / \mathrm{L}$, which remarkably shortened the QTcB from $526 \mathrm{~ms}$ to $423 \mathrm{~ms}$.

In our 10 patients treated with spironolactone high dose+, plasma potassium increased from $4.1 \mathrm{mmol} / \mathrm{L}$ 
A

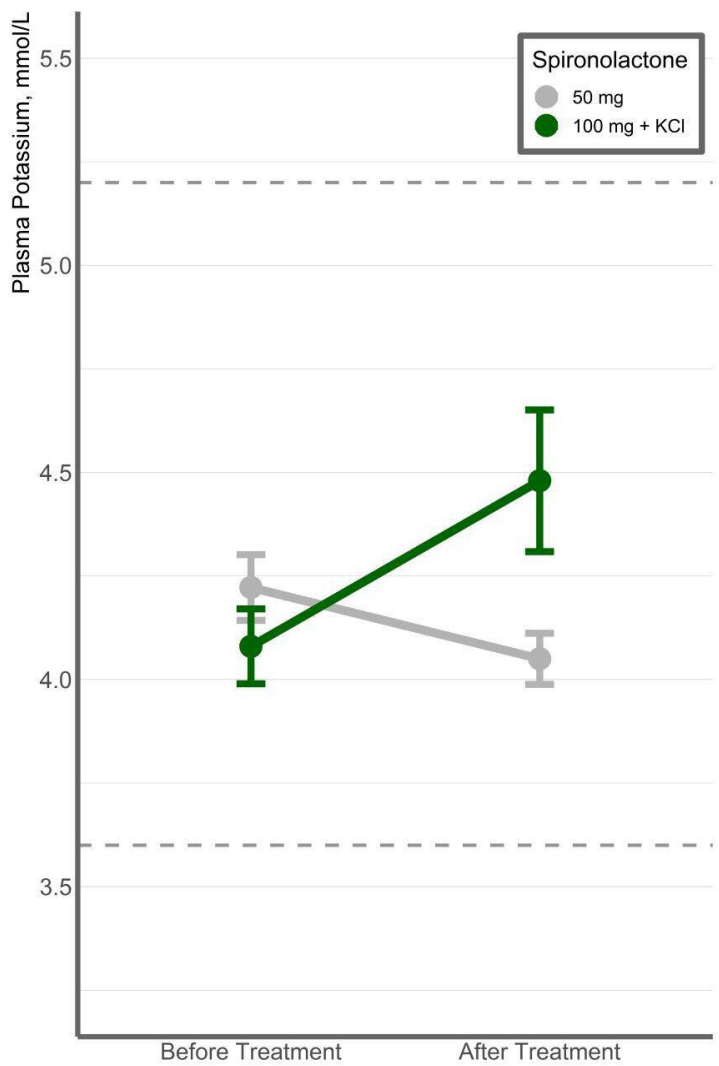

B

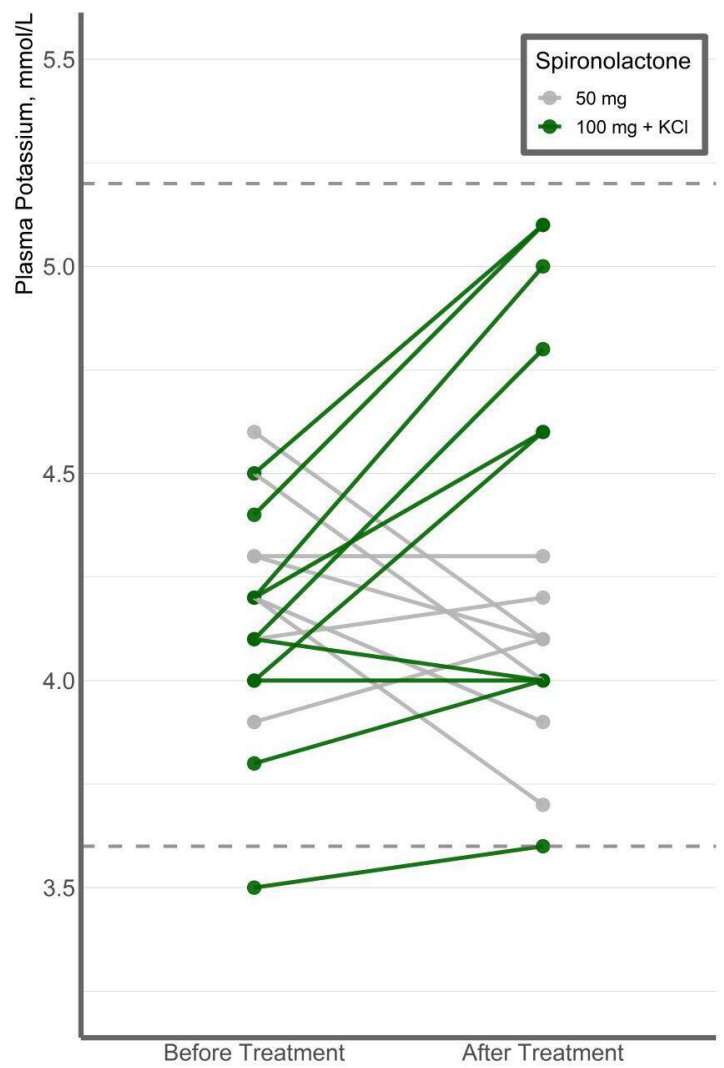

Figure 1 Mean (A) and individual (B) changes of plasma potassium in response to potassium-elevating treatment. Adding 50 $\mathrm{mg}$ spironolactone to the usual beta-blocker treatment did not change plasma potassium levels, but $100 \mathrm{mg}$ spironolactone and potassium chloride significantly increased plasma potassium from 4.08 to $4.48 \mathrm{mmol} / \mathrm{L}$.

to $4.5 \mathrm{mmol} / \mathrm{L}$ but did not shorten the repolarisation at rest. As brisk standing, inducing a sudden brief tachycardia, has been suggested as a diagnostic test for LQTS, ${ }^{8}$ we included this method in our study. In response to brisk standing, heart rate increased by $22-25$ beats $/ \mathrm{min}$, but from slightly different resting heart rates. To assess impact on repolarisation, and not only to capture differences in response to heart rate changes, the more conservative Fridericia's correction was preferred. Still, no differences in QTcF at maximum heart rate were found, demonstrating that also the ability to adapt repolarisation in response to rapid changes in heart rate was unaffected by potassium-elevating treatment. To further elaborate on the impact of treatment, Bazett's correction (QTcB), automatic measures of QTcF and T-wave morphology were also assessed-finding similar negative results.

Besides a potentially beneficial effect on repolarisation, four other important factors should be considered if potassium-elevating treatment could be used for antiarrhythmic prophylaxis: (1) risk of hyperkalaemia, (2) antiarrhythmic potential, (3) effect on blood pressure and (4) feasibility.

After the study by Etheridge $e t a l^{4}$ was published, Goldenberg and $\operatorname{Moss}^{6}$ set up a randomised trial with the suggested doses, but the study was terminated early due to risk of hyperkalaemia. Unfortunately, the data from the trial was never published but only mentioned in a correspondence letter. ${ }^{6}$ Therefore, as a compromise, our study aimed to use doses that would be feasible to initiate without intense monitoring of potassium concentration. In our cohort, $50 \mathrm{mg}$ of spironolactone did not increase plasma potassium, which was only accomplished in the treatment group taking $100 \mathrm{mg}$ and potassium supplements. The increase was only one-third of the increase reported in the study by Etheridge $e t a l$, which correspond well with the smaller doses used. Although the increase in plasma potassium varied from patient to patient-no patients in our study developed hyperkalaemia as the maximum concentration was $5.1 \mathrm{mmol} / \mathrm{L}$. In contrast, Etheridge et al reported that 3/8 developed serum potassium $\geq 5.5 \mathrm{mmol} / \mathrm{L}$. Importantly, in this study plasma potassium is used, which is measured approximately 0.4 $\mathrm{mmol} / \mathrm{L}$ lower compared with serum potassium used in previous studies. $^{12}$

The concept of using potassium-elevating treatment suggested by Etheridge $e t$ al was based on a Xenopus oocytes study, describing a paradoxically linear correlation between increasing HERG current amplitude and increasing extracellular potassium concentration. ${ }^{13}$ However, shortening of the QT interval is merely a proxy of arrhythmic risk, and no current data support that potassium-elevating treatment, in patients with a potassium concentration within normal range, translate into a lower risk of arrhythmias. Importantly, the correlation 
A) In Usual Treatment with 150 mg Metroprolol /day

Plasma-K+: $4.2 \mathrm{mmol} / \mathrm{L}$

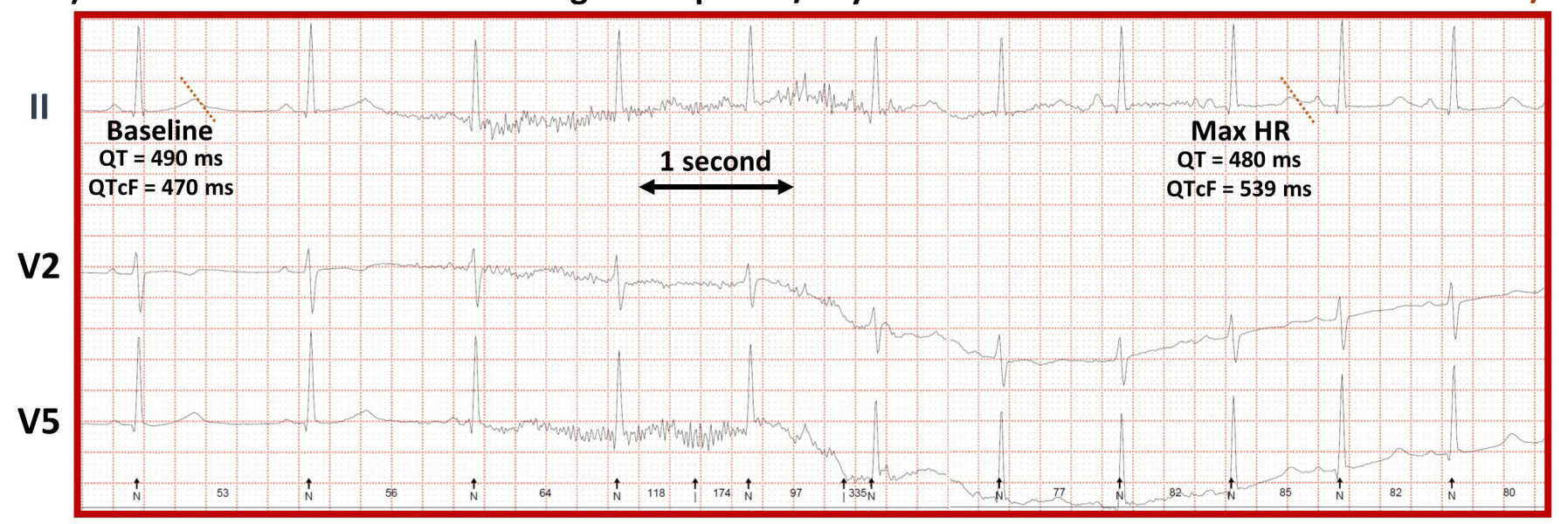

B) + $\mathbf{1 0 0}$ mg Spironolactone and $\mathbf{3}$ g Potassium Chloride /day

Plasma- $\mathrm{K}^{+}$: $4.6 \mathrm{mmol} / \mathrm{L}$

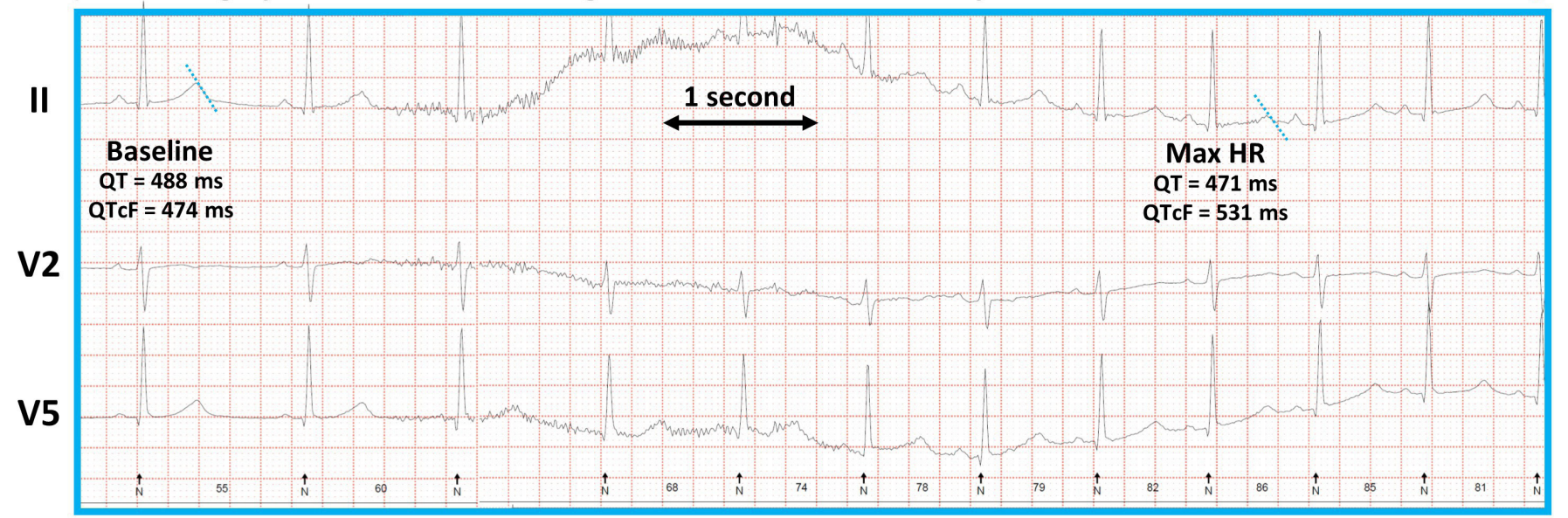

Figure 2 ECG examples of a patient treated with $100 \mathrm{mg}$ spironolactone and $3 \mathrm{~g}$ potassium chloride in addition to usual betablocker treatment. QT intervals are shown at rest and at maximum heart rate during standing. (A) ECG recording in usual betablocker treatment and (B) ECG after 1 week of potassium-elevating treatment.

between potassium concentration and ventricular arrhythmias has recently been investigated by Pezhouman et al in rabbit hearts. ${ }^{14}$ They found a sigmoid correlation between ventricular arrhythmias and potassium concentration-suggesting a limited antiarrhythmic potential of elevating serum potassium concentration higher than $\sim 4.0 \mathrm{mmol} / \mathrm{L}^{14}$

Hypokalaemia is a well-known risk factor for arrhythmias in patients with LQTS and guidelines recommend correction of electrolyte abnormalities if the patients develops, for example, diarrhoea or vomiting. ${ }^{2}$ Therefore, it would be fair to speculate that potassium-elevating treatment may prevent episodes of hypokalaemia-indirectly serving as a antiarrhythmic treatment. Still, this theoretical effect would need to be tested against a pillin-the-pocked approach with orally administered potassium supplement-carefully considering effect versus side effects and feasibility.

In current guidelines, ${ }^{2}$ beta blockers are the first-line treatment, and a potential role for potassium-elevating treatment would be as supplement to this. However, with both beta blockers and spironolactone-both lowering blood pressure-the risk of hypotension should be considered. Unfortunately, Etheridge et at did not report blood pressure at baseline or after treatment, despite one patient developing orthostatic dizziness. In our cohort, a significant drop in systolic blood pressure was found in both treatment groups, but none reported dizziness as a side effect, which may be explained by the young age in our cohort. On the other hand, 6/20 patients developed other side effects, and though only one patient self-discontinued treatment due to severe influenza-like symptoms, long-term treatment would be prohibitive in a non-neglectable number of patients. Additionally, as previously demonstrated in patients with heart failure, both our treatment groups had a significant reduction of eGFR in response to potassium-elevating treatment, which could have long-term complications in patients with LQTS with chronic kidney failure. ${ }^{15}$

Finally, it is important to consider feasibility in a realworld setting. Our high dose+ group, experiencing an 0.4 $\mathrm{mmol} / \mathrm{L}$ increase in plasma potassium, was given six extra tablets per day $(4 \times 750 \mathrm{mg}$ kaleorid $+2 \times 50 \mathrm{mg}$ spironolactone $=42$ tables total for the week) - on top of regular 

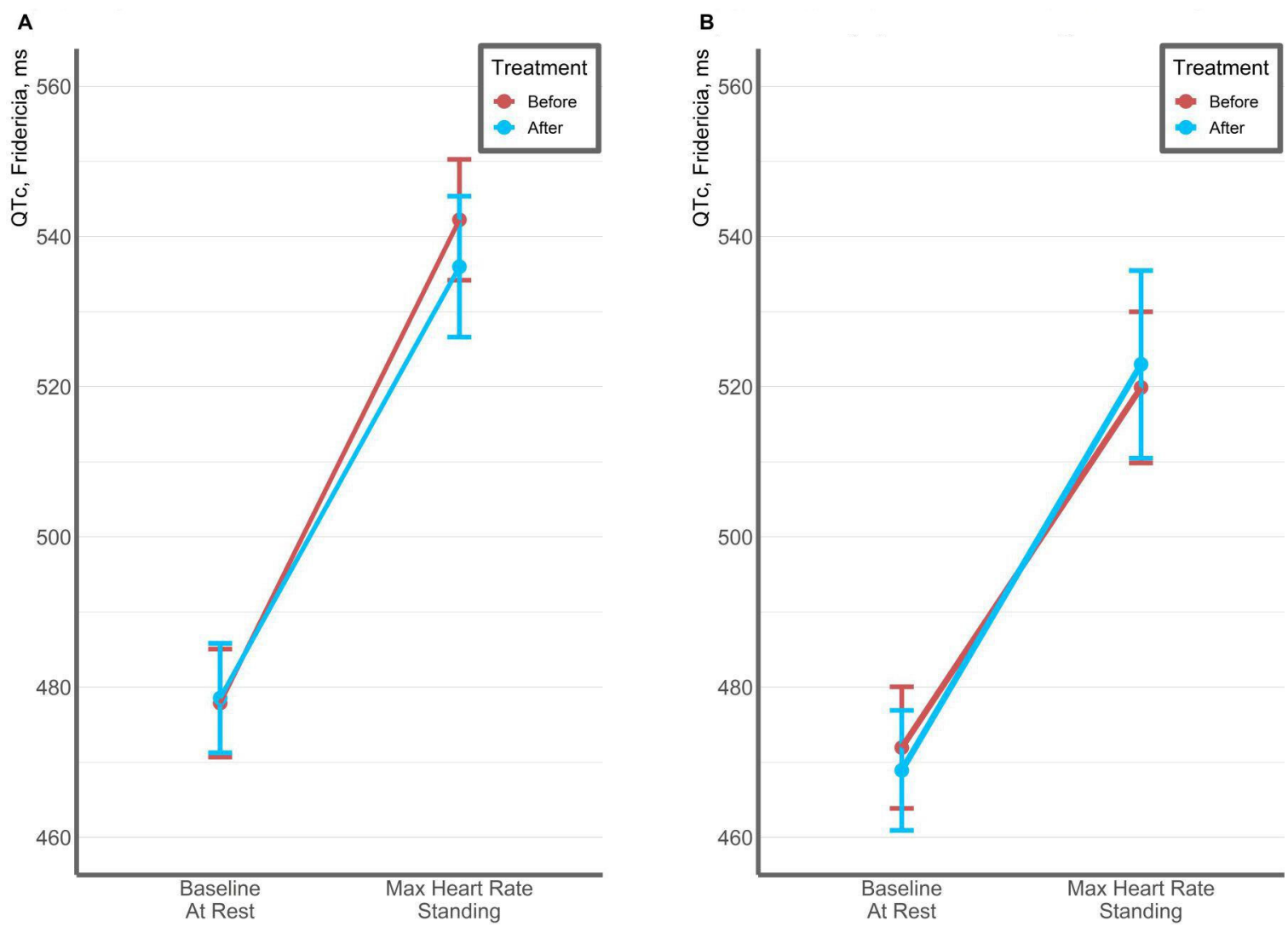

Figure 3 Effect of potassium-elevating treatment in different doses on QTcF interval at rest and at maximum heart rate during brisk standing. (A) The QTcF response to brisk standing is shown on the left, before versus after treatment with 50 mg spironolactone. (B) The QTcF response to brisk standing is shown on the right, before versus after treatment with $100 \mathrm{mg}$ spironolactone $+3 \mathrm{~g}$ potassium chloride.

treatment. All 19 patients completing our study reported full compliance, but our study period was also limited to only 7 days. In Denmark, the available potassium supplement 'kaleorid' $750 \mathrm{mg}$ contains $10 \mathrm{mmol}$ potassium. To meet the suggested doses from previous studies, patients would need to intake $\sim 20$ kaleorid and spironolactone tablets per day in addition to regular medication.

It is highly questionable if such drug loads are feasible as long-term treatment, especially considering that WaddellSmith et al found that $50 \%$ of patients with LQTS had suboptimal beta-blocker compliance and only $13 \%$ had ideal compliance. ${ }^{16}$ At the same time, most arhrythmic events have been found to occur in the non-compliant patients. ${ }^{17}$ Taking into account, the questionable effect of moderate doses of potassium-elevating drugs, risk of hyperkalaemia and side effects-efforts are possibly better spent at securing a high beta-blocker compliance in patients with normal electrolyte balance than to experiment with a new complicated regime that may compromise compliance.

\section{Limitations}

Although this is the largest study on potassium-elevating treatment in LQTS, we were limited by a low number of participants. Compared with previous studies, patients had shorter baseline QT intervals. Our cohort may therefore more accurately represent the modern patients with
LQTS but may have underestimated the shortening effect of treatment on repolarisation of a more malignant cohort. Optimally, patients would have had hypokalaemia at baseline before increasing potassium levels as this would have potentially shown a greater effect on the QT interval. Hence, larger studies on patients with LQTS are needed to show the benefits of potassiumelevating treatment not only in relation to QT-interval duration and safety but also for assessment of the effect on arrhythmia.

Also, our study included only 1 week of treatment, and no restrictions were made regarding food containing more or less potassium. Also, no control group was included as the previous study did not find an effect on repolarisation in controls-even in much higher doses. ${ }^{5}$ Therefore, it was not considered ethically acceptable to administer up to 49 tablets (beta blocker +spironolactone+potassium chloride) to healthy participants in just 1 week.

Last, treatment with the betal selective beta blockers, metoprolol and atenolol, have for many years been standard in Denmark. Therefore, it may be hypothesised that the amount of potassium increase is underestimated ${ }^{18}$ as compared with treatment with the non-selective nadolol, which is recommended as antiarrhythmic treatment by several newer studies. ${ }^{19-21}$ 


\section{CONCLUSION}

In this study, we tested the effect of potassium-elevating treatment on repolarisation in patients with LQTS. We demonstrate that $100 \mathrm{mg}$ spironolactone and potassium supplements increased plasma potassium by $0.4 \mathrm{mmol} / \mathrm{L}$ without any cases of hyperkalaemia. However, this modest increase did not shorten cardiac repolarisation in static or dynamic ECG recordings. In addition, more than one-fourth experienced side effects. Considering that potassium-elevating treatment has been suggested as antiarrhythmic treatment solely based on shortening of the repolarisation, our data do not support that moderate elevation of plasma potassium has a role for long-term antiarrhythmic prophylaxis in patients with LQTS with normal potassium levels.

Contributors PM and JT drafted the article and contributed to the conception or design of the work and the final approval of the version to be published. PM and KA contributed to the data collection. PM, CG, JKK, AHC, HB and JT contributed to the data analysis and interpretation. KA, JKK, CG, AHC and HB contributed to the critical revision of the article.

Funding This research was supported by the Danish Heart Foundation (grant number 17-R115-A7532-22065), the Lundbeck Foundation (R358-2020-2343), Fondsbørsvekselerer Henry Hansen og hustrus legat, the FUKAP Foundation, A.P. Møller og Hustru Chastine Mc-Kinney Møllers Fond til Almene Formaal and Købmand Sven Hansen og Hustru Ina Hansens Fond.

Competing interests None declared.

Patient consent for publication Not required.

Ethics approval The study was performed in accordance with the Helsinki Declaration and approved by the regional ethics committee, Capital Region of Denmark ( $\mathrm{H}-17004681)$. Written consent was obtained before enrolment ( Clinicaltrials.gov). The data underlying this article are available in the article and in its online supplemental material.

Provenance and peer review Not commissioned; externally peer reviewed.

Data availability statement No data are available. All data relevant to the study are included in the article or uploaded as supplementary information.

Open access This is an open access article distributed in accordance with the Creative Commons Attribution Non Commercial (CC BY-NC 4.0) license, which permits others to distribute, remix, adapt, build upon this work non-commercially, and license their derivative works on different terms, provided the original work is properly cited, appropriate credit is given, any changes made indicated, and the use is non-commercial. See: http://creativecommons.org/licenses/by-nc/4.0/.

ORCID iD

Peter Marstrand http://orcid.org/0000-0003-1766-181X

\section{REFERENCES}

1 Moss AJ, Zareba W, Hall WJ, et al. Effectiveness and limitations of beta-blocker therapy in congenital long-QT syndrome. Circulation 2000;101:616-23.
2 Priori SG, Wilde AA, Horie M, et al. Executive summary: HRS/ EHRA/APHRS expert consensus statement on the diagnosis and management of patients with inherited primary arrhythmia syndromes. Europace 2013:15:1389-406.

3 Al-Khatib SM, Stevenson WG, Ackerman MJ, et al. 2017 AHA ACC/HRS guideline for management of patients with ventricular arrhythmias and the prevention of sudden cardiac death: a report of the American College of Cardiology/American heart association Task force on clinical practice guidelines and the heart rhythm Society. Circulation 2018;138:e272-391.

4 Etheridge SP, Compton SJ, Tristani-Firouzi M, et al. A new oral therapy for long QT syndrome: long-term oral potassium improves repolarization in patients with hERG mutations. J Am Coll Cardiol 2003;42:1777-82.

5 Compton SJ, Lux RL, Ramsey MR, et al. Genetically defined therapy of inherited long-QT syndrome. correction of abnormal repolarization by potassium. Circulation 1996;94:1018-22.

6 Goldenberg I, Moss AJ. Reply. J Am Coll Cardiol 2008;52:1605-6.

7 Marstrand P, Almatlouh K, Kanters JK, et al. Long QT syndrome type 1 and 2 patients respond differently to arrhythmic triggers: The TriQarr in vivo study. Heart Rhythm 2021;18:241-9.

8 Viskin S, Postema PG, Bhuiyan ZA, et al. The response of the QT interval to the brief tachycardia provoked by standing: a bedside test for diagnosing long QT syndrome. J Am Coll Cardiol 2010;55:1955-61.

9 Postema PG, De Jong JSSG, Van der Bilt IAC, et al. Accurate electrocardiographic assessment of the QT interval: teach the tangent. Heart Rhythm 2008:5:1015-8.

10 Graff C, Andersen MP, Xue JQ, et al. Identifying drug-induced repolarization abnormalities from distinct ECG patterns in congenital long QT syndrome: a study of sotalol effects on T-wave morphology. Drug Saf 2009;32:599-611.

11 R Development Core Team R. R: A Language and Environment for Statistical Computing, version 3.6.1. R Found Stat Comput [Internet]. , 2019: 1, 409. http://www.r-project.org

12 Nijsten MW, de Smet BJ, Dofferhoff AS. Pseudohyperkalemia and platelet counts. N Engl J Med 1991;325:1107.

13 Sanguinetti MC, Jiang C, Curran ME, et al. A mechanistic link between an inherited and an acquired cardiac arrhythmia: hERG encodes the IKr potassium channel. Cell 1995;81:299-307.

14 Pezhouman A, Singh N, Song Z, et al. Molecular basis of Hypokalemia-Induced ventricular fibrillation. Circulation 2015;132:1528-37.

15 Beldhuis IE, Myhre PL, Claggett B, et al. Efficacy and Safety of Spironolactone in Patients With HFpEF and Chronic Kidney Disease. JACC Heart Fail 2019;7:25-32.

16 Waddell-Smith KE, Li J, Smith W, et al. $\beta$-Blocker Adherence in Familial Long QT Syndrome. Circulation 2016;9.

17 Vincent GM, Schwartz PJ, Denjoy I, et al. High efficacy of betablockers in long-QT syndrome type 1: contribution of noncompliance and QT-prolonging drugs to the occurrence of beta-blocker treatment "failures". Circulation 2009;119:215-21.

18 Brown MJ, Brown DC, Murphy MB. Hypokalemia from beta2receptor stimulation by circulating epinephrine. N Engl J Med 1983;309:1414-9.

19 Abu-Zeitone A, Peterson DR, Polonsky B, et al. Efficacy of different beta-blockers in the treatment of long QT syndrome. J Am Coll Cardiol 2014;64:1352-8.

20 Chockalingam P, Crotti L, Girardengo G, et al. Not all beta-blockers are equal in the management of long QT syndrome types 1 and 2: higher recurrence of events under metoprolol. J Am Coll Cardiol 2012;60:2092-9.

21 Mazzanti A, Maragna R, Vacanti G, et al. Interplay Between Genetic Substrate, QTc Duration, and Arrhythmia Risk in Patients With Long QT Syndrome. J Am Coll Cardiol 2018;71:1663-71. 